\title{
UVolution, a Photochemistry Experiment in Low Earth Orbit: Investigation of the Photostability of Carboxylic Acids Exposed to Mars Surface UV Radiation Conditions
}

\author{
Fabien Stalport,, ${ }^{1,2}$ Yuan Yong Guan,, Patrice Coll, ${ }^{1}$ Cyril Szopa, ${ }^{3}$ Frédérique Macari, \\ François Raulin, Didier Chaput, ${ }^{4}$ and Hervé Cottin ${ }^{1}$
}

\begin{abstract}
The detection and identification of organic molecules on Mars are of prime importance to establish the existence of a possible ancient prebiotic chemistry or even a biological activity. To date, however, no complex organic compounds have been detected on Mars. The harsh environmental conditions at the surface of Mars are commonly advocated to explain this nondetection, but few studies have been implemented to test this hypothesis. To investigate the nature, abundance, and stability of organic molecules that could survive under such environmental conditions, we exposed, in low Earth orbit, organic molecules of martian astrobiological relevance to solar UV radiation $(>200 \mathrm{~nm})$. The experiment, called UVolution, was flown on board the Biopan ESA module, which was situated outside a Russian Foton automated capsule and exposed to space conditions for 12 days in September 2007. The targeted organic molecules [ $\alpha$-aminoisobutyric acid (AIB), mellitic acid, phthalic acid, and trimesic acid] were exposed with, and without, an analogous martian soil. Here, we present experimental results of the impact of solar UV radiation on the targeted molecules. Our results show that none of the organic molecules studied seemed to be radiotolerant to the solar UV radiation when directly exposed to it. Moreover, the presence of a mineral matrix seemed to increase the photodestruction rate. AIB, mellitic acid, phthalic acid, and trimesic acid should not be considered as primary targets for in situ molecular analyses during future surface missions if samples are only collected from the first centimeters of the top surface layer. Key Words: Space mission-Mars-Astrobiology—UV radiation-Organic matter. Astrobiology 10, 449-461.
\end{abstract}

\section{Introduction}

$\mathbf{M}$ ARS IS A PRIMARY TARGET of astrobiological interest: its past environmental conditions may have been favorable to the emergence of a prebiotic chemistry and, possibly, biological activity. Since 2004, several space missions (Mars Exploration Rovers, Mars Express, Phoenix, and Mars Reconnaissance Orbiter) have provided data that suggest liquid water, an essential ingredient for life as we know it, was present on Mars throughout its first 500 million years of existence (Squyres et al., 2004; Bibring et al., 2006). In situ exploration is currently underway at the surface of Mars, and specific studies have been implemented to determine whether life is, or has been, present. In this context, the detection of organic molecules is of critical importance in that they are known to be among the best biosignatures, that is, indicators of past or present biological activity. To date, the only hydrocarbon tentatively detected on Mars is methane, which, according to recent studies, occurs at an extremely low concentration (Formisano et al., 2004; Krasnopolsky et al., 2004). The presence of methane on Mars can be attributed to biotic or abiotic processes. More-complex organic material, which would be a signature of a prebiotic chemistry or even a biological activity, typically has lower volatilities and may be present in the regolith where its detection requires in situ measurements at the Mars surface.

To date, the only in situ space experiment devoted to the detection of organic molecules has been the gas

\footnotetext{
${ }^{1}$ Laboratoire Interuniversitaire des Systèmes Atmosphériques (LISA), UMR 7583 CNRS, Universities of Paris 7 and Paris 12, Créteil, France.

${ }^{2}$ NASA Goddard Space Flight Center (GSFC), Greenbelt, Maryland.

${ }^{3}$ UPMC University of Paris 6; Université Versailles St-Quentin; CNRS/INSU, LATMOS-IPSL, Paris, France.

${ }^{4}$ Centre National d'Etudes Spatiales, Toulouse, France.
} 
chromatograph-mass spectrometer (GCMS) experiment of the Viking missions. With this experiment, several surface samples, collected down to approximately $10 \mathrm{~cm}$ depth, were heated to temperatures up to $500^{\circ} \mathrm{C}$, and the gases released during the pyrolysis experiments were analyzed with the GCMS instruments. No organic molecules of martian origin were identified at the two different landing sites within the detection limits of the instruments (Biemann et al., 1976, 1977). These results are difficult to explain since several different mechanisms could have contributed to the accumulation of complex organic material on Mars:

(i) The past surface environmental conditions may have been favorable to the emergence of life or a prebiotic chemistry. Organic records of a past/present biological activity could still be present on the surface of Mars (Simoneit et al., 1998).

(ii) Laboratory investigations (Hubbard et al., 1971, 1973) and photochemical models (Wong et al., 2004) have predicted the possible formation of organic gaseous compounds in Mars' current atmosphere, mainly formaldehyde, ethane, and methanol. Such processes could also have been more efficient in the past when the atmosphere of Mars was denser and possibly more reducing than the present atmosphere. Atmospheric organics produced in the past may have accumulated in the soil and survived to the present.

(iii) Comets, meteorites, and micrometeorites are known to contain numerous organic compounds (Clemett et al., 1998; Cottin et al., 1999; Botta and Bada, 2002; Glavin et al., 2004; Pizzarello et al., 2006) that are still being delivered to Earth and possibly other planets today via soft impacts. Therefore, it is possible that at least some organic molecules originating from those exogenous sources should have been detected at the martian surface.

There are different possible interpretations as to why organics were never detected in the soil of Mars analyzed with the GCMS experiment. The most straightforward conclusion is that there were no organic species in the samples to begin with. Another possible explanation is that the pyrolysis GCMS experiment used by Viking was not optimized for the detection of several key classes of organic compounds at trace levels (Navarro-Gonzalez et al., 2006). The harsh martian environment could also explain the lack of organics if conditions are such that they are destroyed. In this context, several experimental and numerical modeling studies were performed to evaluate the possibility for the destruction and/or evolution of the organics under martian surface environmental conditions (Oro and Holzer, 1979; Stoker and Bullock, 1997; ten Kate et al., 2005, 2006; Stalport et al., 2008, 2009). Solar UV radiation is a major source of energy that can initiate chemical evolution of organics and has been proposed as an explanation for the lack of organics at the surface of Mars. Laboratory-based UV radiation experiments are a good support for such studies, especially because it is possible to control parameters such as the flux and spectrum of UV sources and the temperature of samples. However, there is no available UV source that perfectly reproduces the martian UV flux and spectrum. To complete and validate such studies, it is important to couple them with in situ ex- periments in which at least an adequate UV spectrum is used. Indeed, the UV spectrum that reaches the surface of Mars is similar to the solar UV spectrum in low Earth orbit in the 200-400 $\mathrm{nm}$ range (Patel et al., 2002).

The present study was supported by results obtained by the low Earth orbit UVolution experiment, which was developed by the Laboratoire Interuniversitaire des Systèmes Atmosphériques (LISA), the Laboratoire ATmosphères Milieux Observations Spatiales (LATMOS), and supported by the European and French Space Agencies (ESA and CNES). The UVolution experiment was part of the Biopan-6 payload set outside the Foton-M3 Russian automated capsule that, for 12 days in September 2007, orbited Earth at roughly $300 \mathrm{~km}$ altitude. Biopan is an ESA exposure facility that enables a direct exposure of various samples to space conditions (Barbier et al., 2002; Demets et al., 2005). The UVolution experiment allows for exposure of organic material to solar UV similar to that which occurs on comets, meteorites, Mars, and Titan. The present study focuses on the results that pertain to the preservation potential of the organic matter relative to conditions on Mars and the way in which the organics were altered during the experiment. The relevance of the experimental conditions and findings to the preservation potential on Mars is discussed. These results also have relevance for the interpretation of possible biosignatures obtained from instruments such as the Sample Analysis at Mars instrument on the Mars Science Laboratory rover (Cabane et al., 2004) and the Mars Organic Molecule Analyzer instrument on the ExoMars rover.

\section{Materials and Methods}

Several key organic molecules of interest with regard to Mars have been selected for the UVolution mission. They are presented in Table 1.

As the number of samples was limited (16 exposition spots available for Mars-related organic samples), sample selection centered on the following carboxylic acids: mellitic, phthalic, and trimesic acids. Indeed, the surface of Mars is considered to be an oxidative environment, and it is hypothesized that one or more oxidants that could destroy organic matter are present in the regolith. This reactivity could be attributed to the presence of catalyzers, one or more inorganic superoxides or peroxides in the martian regolith (Chun et al., 1978; Pang et al., 1982; Yen et al., 2000), $\mathrm{H}_{2} \mathrm{O}_{2}$ [recently detected (Clancy et al., 2004; Encrenaz et al., 2004)] diffusion into the regolith (Bullock et al., 1994), or the presence of perchlorates (Hecht et al., 2009). Results of a theoretical study led by Benner et al. (2000) with regard to the oxidative action on organic molecules of meteoritic origin in the martian soil show that such compounds should not be entirely oxidized into volatile molecules (i.e., $\mathrm{CO}_{2}$ and $\mathrm{H}_{2} \mathrm{O}$ ). The described chemical pathways show that such organics would be converted into carboxylic acids. Such acids should be metastable intermediates of meteoritic organics under oxidizing conditions. Among these carboxylic acids, mellitic acid appears to be the most interesting; our laboratory studies showed that the evolution of this molecule produces a radiotolerant organic compound (Stalport et al., 2009).

We also selected one amino acid, $\alpha$-aminoisobutyric acid (AIB), for this study since it is one of the main amino acids in both meteoritic and micrometeoritic material (Brinton et al., 
Table 1. Description of the SAmples

Molecule
AIB ( $\alpha$-aminoisobutyric acid)
AIB with soil
Phthalic acid
(1,2-benzenedicarboxylic acid)

Phthalic acid with soil

Trimesic acid

(1,3,5-benzenetricarboxylic acid)

Trimesic acid with soil

Mellitic acid

(benzenehexacarboxylic acid)

Mellitic acid with soil
Description

Sample 1 Exposed

Sample 2 Exposed

Sample 3 Not exposed

Sample 4 Not exposed

Sample 5 Ground

Sample 6 Ground

Sample 7 Ground

Sample 8 Ground

Sample 1 Exposed

Sample 2 Exposed

Sample 3 Not exposed

Sample 4 Not exposed

Sample 5 Ground

Sample 6 Ground

Sample 7 Ground

Sample 8 Ground

Sample 1 Exposed

Sample 2 Exposed

Sample 3 Not exposed

Sample 4 Not exposed

Sample 5 Ground

Sample 6 Ground

Sample 7 Ground

Sample 8 Ground

Sample 1 Exposed

Sample 2 Exposed

Sample 3 Not exposed

Sample 4 Not exposed

Sample 5 Ground

Sample 6 Ground

Sample 7 Ground

Sample 8 Ground

Sample 1 Exposed

Sample 2 Exposed

Sample 3 Not exposed

Sample 4 Not exposed

Sample 5 Ground

Sample 6 Ground

Sample 7 Ground

Sample 8 Ground

Sample 1 Exposed

Sample 2 Exposed

Sample 3 Not exposed

Sample 4 Not exposed

Sample 5 Ground

Sample 6 Ground

Sample 7 Ground

Sample 8 Ground

Sample 1 Exposed

Sample 2 Exposed

Sample 3 Not exposed

Sample 4 Not exposed

Sample 5 Ground

Sample 6 Ground

Sample 7 Ground

Sample 8 Ground

Sample 1 Exposed

Sample 2 Exposed

Sample 3 Not exposed

Sample 4 Not exposed

Sample 5 Ground

Sample 6 Ground

Sample 7 Ground

Sample 8 Ground
Variation area $\left(4000-2080 \mathrm{~cm}^{-1}\right)$

$-2.2 \%$

$-3.6 \%$

$+3.5 \%$

$\mathrm{N} / \mathrm{A}$

$\mathrm{N} / \mathrm{A}$

$\mathrm{N} / \mathrm{A}$

$\mathrm{N} / \mathrm{A}$

$\mathrm{N} / \mathrm{A}$

$-14.8 \%$

$-8.6 \%$

$-2.4 \%$

$+0.4 \%$

$\mathrm{N} / \mathrm{A}$

N/A

$\mathrm{N} / \mathrm{A}$

N/A

$-10.3 \%$

$-8.9 \%$

$-2.5 \%$

$-2.5 \%$

N/A

$\mathrm{N} / \mathrm{A}$

N/A

$\mathrm{N} / \mathrm{A}$

$-12.7 \%$

$-12.5 \%$

$-2.5 \%$

$-1.6 \%$

N/A

$\mathrm{N} / \mathrm{A}$

$\mathrm{N} / \mathrm{A}$

$\mathrm{N} / \mathrm{A}$

$-24.9 \%$

$-21.8 \%$

$-4.8 \%$

$-7.6 \%$

$\mathrm{N} / \mathrm{A}$

N/A

N/A

N/A

$\mathrm{N} / \mathrm{A}$

N/A

$\mathrm{N} / \mathrm{A}$

N/A

$\mathrm{N} / \mathrm{A}$

$\mathrm{N} / \mathrm{A}$

N/A

$\mathrm{N} / \mathrm{A}$

$-47.2 \%$

$-40.2 \%$

$-10.8 \%$

$-5.4 \%$

N/A

N/A

N/A

N/A

N/A

$\mathrm{N} / \mathrm{A}$

$\mathrm{N} / \mathrm{A}$

$\mathrm{N} / \mathrm{A}$

N/A

$\mathrm{N} / \mathrm{A}$

$\mathrm{N} / \mathrm{A}$

$\mathrm{N} / \mathrm{A}$

The variation of the IR spectra area of each sample is determined by comparison before and after the flight in orbit. Negative: loss. Positive: gain. N/A: not applicable. 


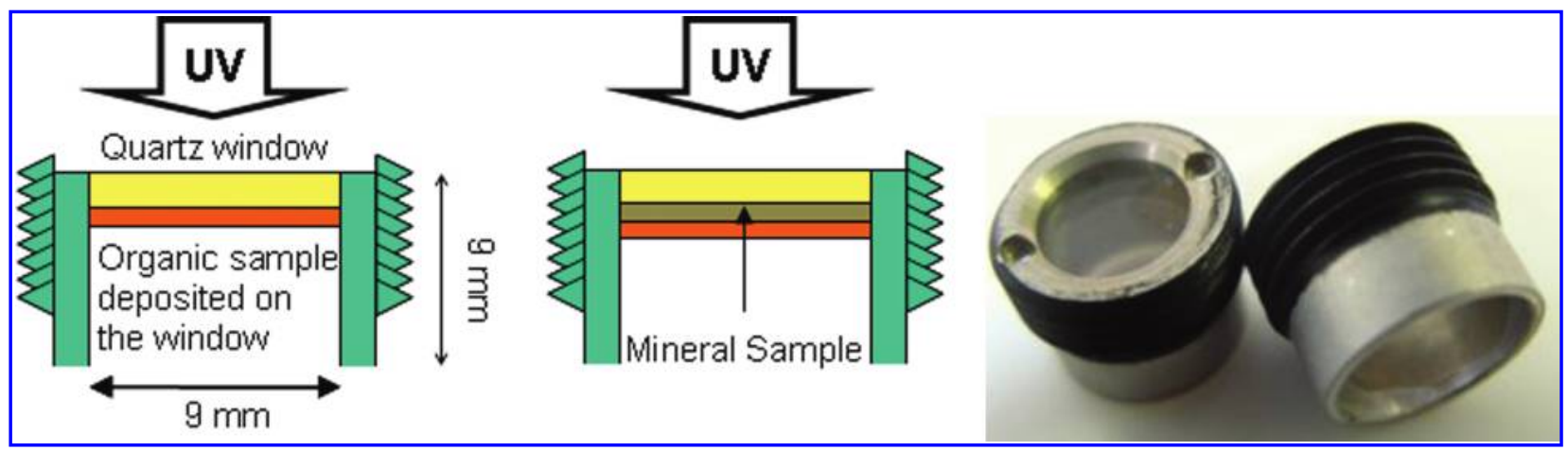

FIG. 1. Left: schematic of the open cells (right: with a mineral matrix, left: without a mineral matrix). Right: picture of the open cells. Color images available online at www.liebertonline.com/ast.

1998; Glavin et al., 2004); therefore it is reasonable to conclude that it could be present on the surface of Mars.

The organic molecules were deposited inside open exposition cells (more details in Cottin et al., 2008). The cells devoted to our "martian" analog samples were composed of a cylindrical aluminum body and a quartz window (thickness: $1 \mathrm{~mm}$, diameter: $9 \mathrm{~mm}$ ). Quartz windows were chosen to mimic the UV spectrum at the surface of Mars. Indeed, UV photons that reach the surface of Mars would be in the 190$400 \mathrm{~nm}$ wavelength range (Kuhn and Atreya, 1979; Cockell et al., 2000; Patel et al., 2002). Quartz is transparent in this wavelength range and absorbs photons below $200 \mathrm{~nm}$.

Two sets of samples were implemented, the first of which consisted of organic molecules that were directly deposited onto the surface of the windows to determine the photolysis rate or the UV resistance of the targeted compound. The second set of samples consisted of windows coated with the organic molecule film, which were positioned underneath a layer of the Mars analog soil JSC Mars-1 (Allen et al., 1998) (Fig. 1). In this way, the mineral matrix was situated between the UV radiation and the film of organic molecules. With this second set of samples, we expected to determine whether the mineral matrix acts as a shield (e.g., via absorption of the UV radiation, which would enhance preservation of the organic compounds) or destruction catalytic effect.

The mineral films were obtained by evaporation; the JSC Mars- 1 soil was sieved ( $<40 \mu \mathrm{m}$ fraction collected) and dispersed by mechanical agitation as a powder in ethanol to prepare a suspension. The solution was then deposited on the window surface beforehand, which was heated to $50^{\circ} \mathrm{C}$ to evaporate the ethanol. Mineral film thickness was about several hundred micrometers (determined by interferometric techniques).

The organic films were prepared in a vacuum sublimation chamber. We obtained homogeneous films with a controlled thickness (a few hundred nanometers, thickness also determined by interferometric techniques). For each sample, the organic films were deposited four times. The windows were kept in an inert atmosphere before being positioned in their cylindrical aluminum tubes and placed into orbit. Two of each type of sample were exposed to solar radiation, whereas two others-used as space dark controls to quantify the contribution of sublimation, thermodecomposition, and thermodesorption-were kept in the dark directly below the exposed deposits (Fig. 2). Four samples of each kind were also prepared and kept in the laboratory as ground controls.
Nevertheless, several seal tightness issues arose with regard to the laboratory samples during storage under pressure. This resulted in extended exposure of the samples to ambient air, which made these ground studies invalid. The ground results therefore are not presented in this article. The action of UV radiation was, however, derived by comparing the results obtained with the flight exposed cells and the flight non-exposed cells.

To determine whether the molecules or the organic films absorbed UV radiation, their UV absorbance spectra were analyzed with a UV/visible spectrophotometer (Perkin Elmer Lambda 2) in the range of $200-400 \mathrm{~nm}$ at $0.5 \mathrm{~nm}$ resolution.

The organic film evolution was determined by Fourier transform infrared spectroscopy (Perkin Elmer-BXII spectrometer resolution: $4 \mathrm{~cm}^{-1}$, number of scans: 8 ). The results are both qualitative and quantitative. For the quantitative measurements, the cells were directly inserted in the measurement compartment of the instrument. The IR spectrum of each sample was obtained by transmission through the quartz window. A background measurement was performed with an empty cell. The acquisition range was set between 4000 and $2080 \mathrm{~cm}^{-1}$ due to the transmission properties of the quartz window in the IR domain. An important part of the

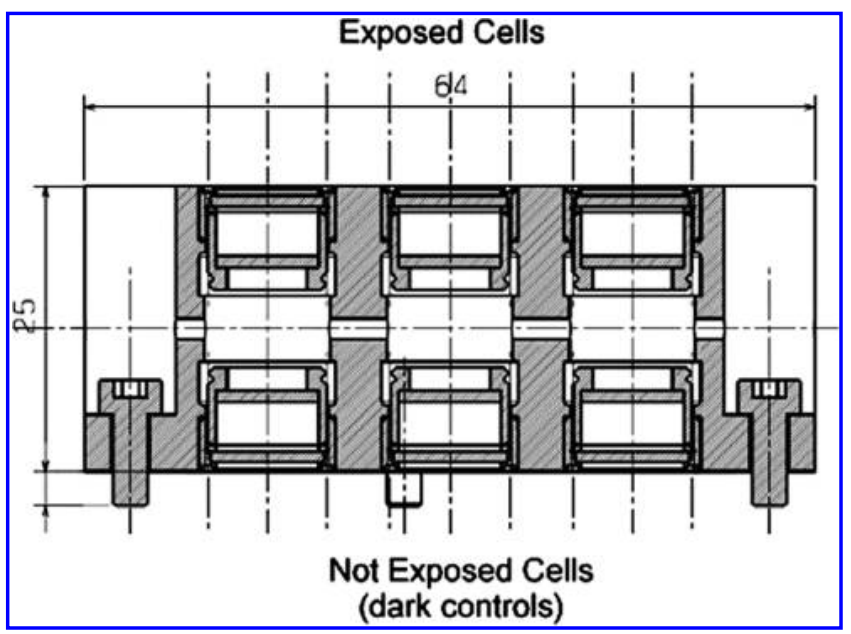

FIG. 2. Schematic of the disposition of the cells. Top: the cells are directly exposed to the solar UV radiation. Bottom: the cells kept in the dark. 


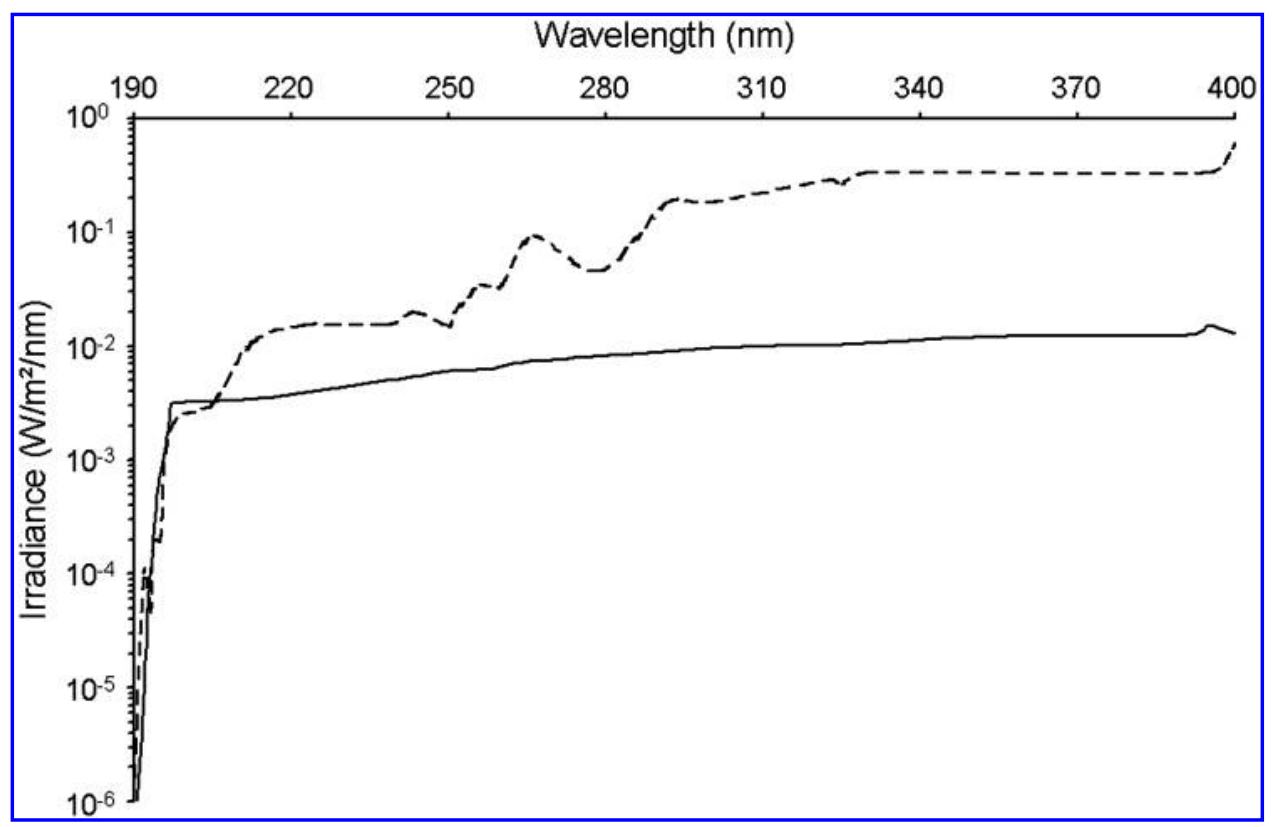

FIG. 3. UV spectrum of the xenon lamp (black line) compared to the solar UV spectrum on the martian surface predicted by Patel et al. (2002) at equatorial noontime (dotted line).

IR domain was then inaccessible. It is important to note that we performed no in situ spectroscopic measurements during the flight. We had two transmission spectra for each sample: one recorded before the flight and one after the flight. We then compared areas of the IR peaks to determine their eventual photolysis rate. These two analyses were separated by 30 days.

For the qualitative measurements, we extracted the quartz windows from the cells after the measurement by transmission. We used an attenuated total reflectance cell composed of a diamond crystal (Golden Gate model, simple reflection, series 10500, Eurolabo Company) adapted with the Fourier transform infrared spectrometer. The samples were deposited on the crystal surface and compacted by a compression anvil to optimize the sample contact with the diamond. The main objective of this second set of analyses was to obtain a more relevant acquisition range. The absorption spectra were obtained in the range of $4000-1000 \mathrm{~cm}^{-1}$. This second IR analysis was important in that it was used to determine whether any new organic compound was produced during exposure to the UV radiation.

Photolysis of the targeted molecules was also implemented in the laboratory. We developed an experiment [Martian Organic Material Irradiation and Evolution (MOMIE), described in Stalport et al., 2009] to study the evolution of organics on Mars. The first step of this project was to reproduce as closely as possible the UV radiation that reaches the martian surface (Fig. 3). We used a UV source that releases photons in the 190-400 $\mathrm{nm}$ wavelength range and focused on a surface of $0.8 \mathrm{~cm}^{2}$ (the surface of a deposit). The UV flux and spectrum were provided by the LOT-ORIEL company and measured with a Jobin Yvon monochromator. For this experiment, the targeted organic molecules were deposited with the vacuum sublimation reactor following the same procedure, but $\mathrm{MgF}_{2}$ windows were used instead of quartz since there was no need for the windows to act as a filter in the UV domain due to the emission spectrum of the labo- ratory lamp and to take advantage of the transmission properties of $\mathrm{MgF}_{2}$ in the IR (down to $1000 \mathrm{~cm}^{-1}$ ). The evolution of the samples was measured by transmission infrared spectroscopy. To date, no experiment with a martian analog soil has been implemented in the laboratory, but it will be the subject of future experiments.

\section{Results}

First, the UV absorption spectra of AIB, phthalic, trimesic, and mellitic acids were determined. These molecules primarily absorb UV radiation in the $200-260 \mathrm{~nm}$ wavelength range (Fig. 4).

\subsection{Transmission results: quantitative data}

The photolysis of an $A$ molecule by UV radiation into new products can be described by the following equation (1):

$$
A \stackrel{h v}{\longrightarrow} \text { products }
$$

This equation can be then mathematically described following Equation 2:

$$
\frac{d[A]}{d t}=-J[A]
$$

If the kinetics of photolysis is of first order (meaning the hypothesis of an optically thin sample in the UV domain, as in these experiments), with $[A]$ the abundance of $A$ molecule, $t$ the irradiation time, and $J$ the photolysis rate ([time $]^{-1}$ ), then this equation can be resolved following Equation 3:

$$
\frac{\operatorname{Ln}[A]_{t}}{\operatorname{Ln}[A]_{0}}=-J \cdot t
$$

By comparing the results obtained for film thicknesses of the same organic molecule (i.e., different $[A]$ ) and the relevant areas of the IR spectra, we obtained a linear correlation 


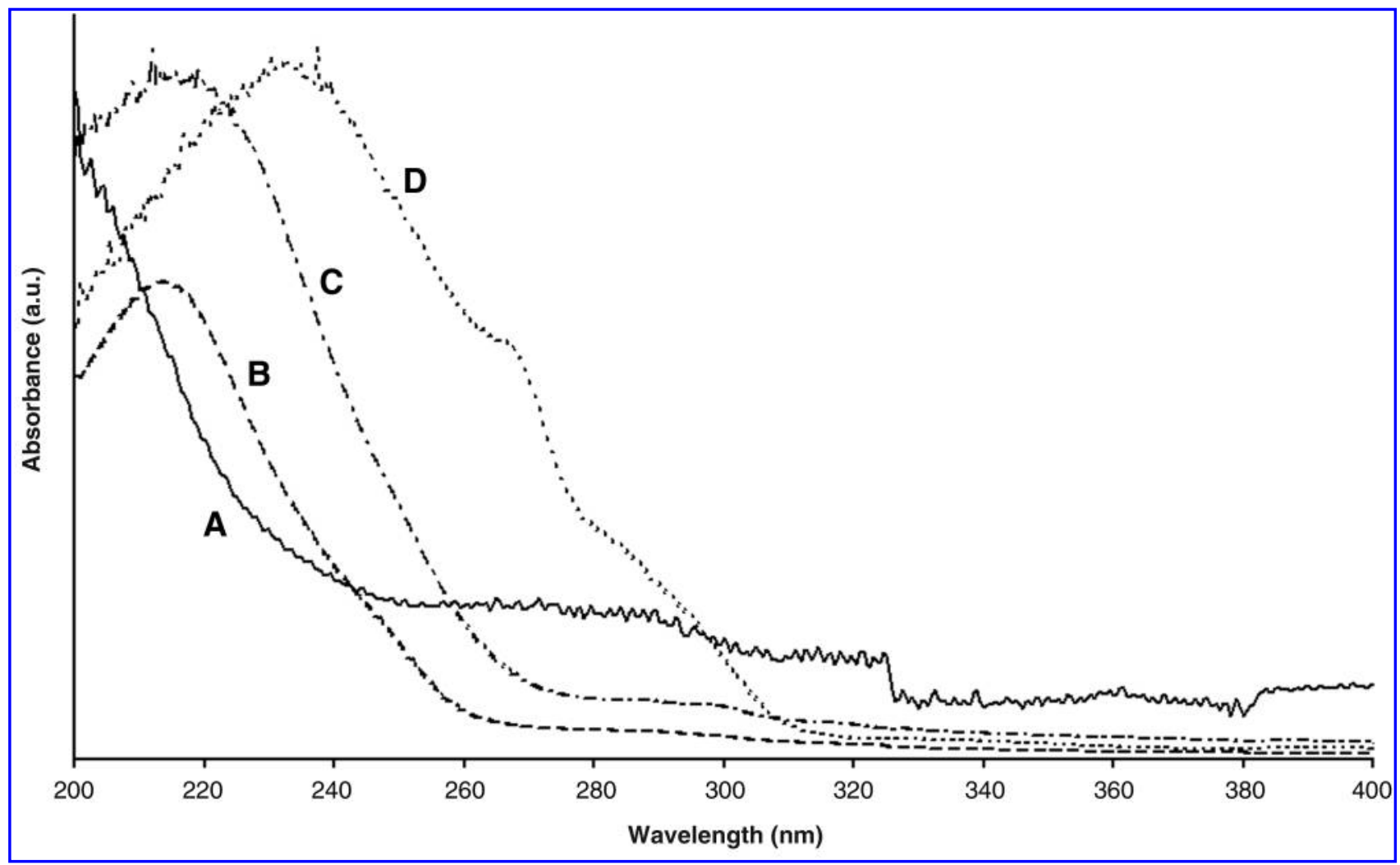

FIG. 4. UV absorption spectra of $\operatorname{AIB}(\mathbf{A})$, trimesic acid (B), mellitic acid (C), and phthalic acid (D). a.u., arbitrary units.

between both of them. Hence, we can determine the abundance of an organic molecule before and after the exposure. The Foton capsule orbiting the Earth freely rotated around its longitudinal axis; thus the samples were not continuously exposed to the Sun. The integrated photolysis time during the experiment in orbit $(t)$ was estimated to be 29 solar constant hours with an uncertainty of $15 \%$ in the $220-280 \mathrm{~nm}$ range. The exposure time was derived from onboard sensors provided by ESA cross-correlated with orbital calculation provided by RedShift Company (St Niklaas, Belgium). This

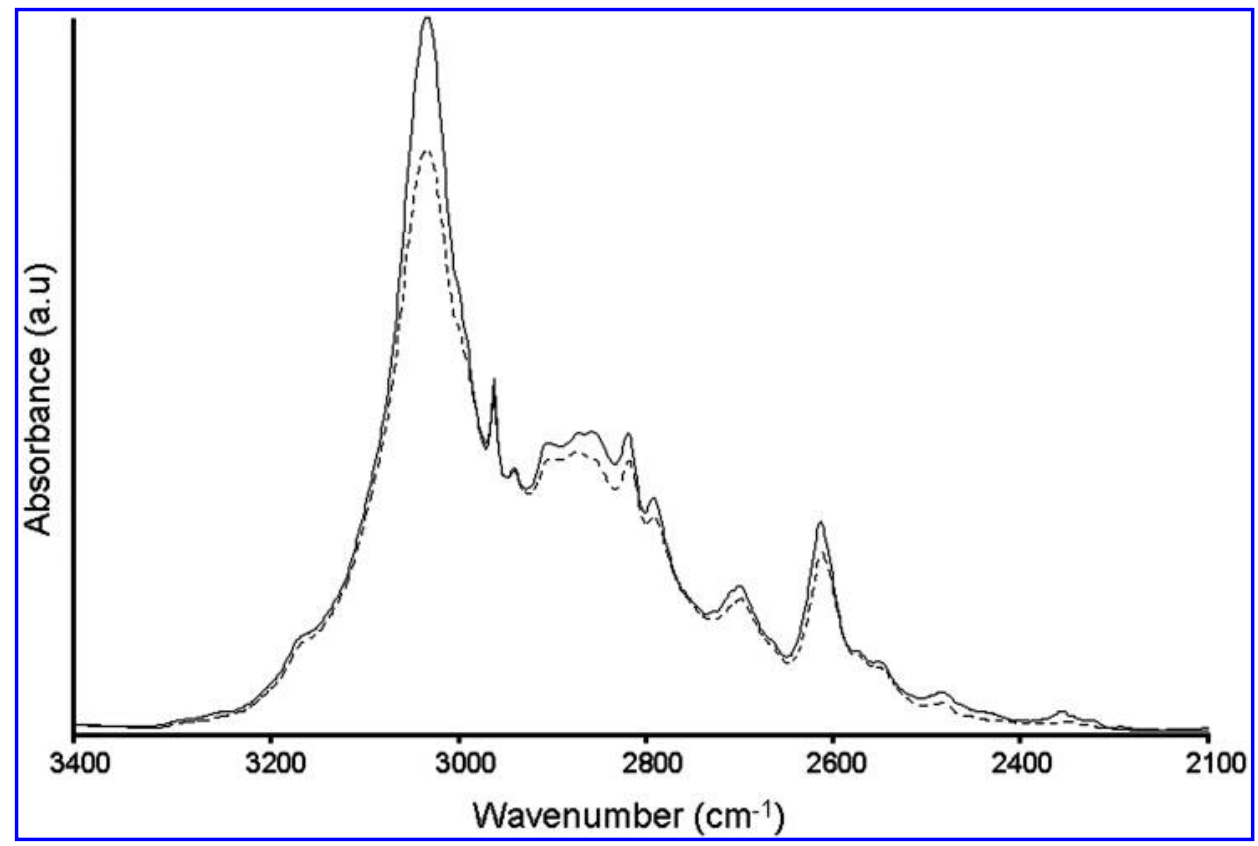

FIG. 5. IR spectra of AIB before (line) and after (dotted line) the flight in orbit in the $4000-2080 \mathrm{~cm}^{-1}$ wavelength range with a $4 \mathrm{~cm}^{-1}$ resolution. 
Table 2. Half-Life Times of the Targeted Compounds FROM THE LOW EARTH ORBIT AND MOMIE EXPERIMENTS

\begin{tabular}{lccc}
\hline & \multicolumn{3}{c}{ Half-life time $(h)$} \\
\cline { 2 - 4 } Molecule & Low orbit & MOMIE & Mars \\
\hline AIB & $290 \pm 75$ & $10 \pm 3$ & $44-1062$ \\
AIB + soil & $184 \pm 81$ & - & $643 \pm 317$ \\
Phthalic acid & $258 \pm 63$ & $41 \pm 7$ & $218-925$ \\
Phthalic acid + soil & $167 \pm 20$ & - & $506 \pm 64$ \\
Trimesic acid & $100 \pm 21$ & $21 \pm 5$ & $122-317$ \\
Trimesic acid + soil & - & - & - \\
Mellitic acid & $43 \pm 10$ & $4 \pm 1$ & $19-169$ \\
Mellitic acid + soil & N/A & - & N/A \\
\hline
\end{tabular}

The rightmost column represents the extrapolation of their halflives under the UV flux expected at the surface of Mars. N/A: not applicable.

corresponds to an amount of UVC equal to $1.2 \pm 0.2$ days with Sun at zenith.

Figure 5 shows the IR spectra of a cell containing AIB before and after exposure in space. Taking into account the variations in the flight dark controls (no loss of AIB by processes of sublimation or thermal decomposition) and the fact that no new spectral feature appears in the spectra, integration of the IR features results in an estimation of the half-life of AIB to be $290 \pm 75 \mathrm{~h}$ ( $2 \sigma$ uncertainty based on time and Fourier transform infrared spectrometer data). We also observed via infrared spectroscopy the partial photodestruction of phthalic, trimesic, and mellitic acids when these compounds were directly exposed to UV radiation. The half-lives of phthalic, trimesic, and mellitic acids are $258 \pm 63$, $100 \pm 21$, and $43 \pm 10 \mathrm{~h}$, respectively (Table 2 ). In contrast to AIB, we observed a loss of these compounds before and after the flight by sublimation or thermal desorption, or both. This loss was taken into consideration when calculating the halflives of these carboxylic acids. The area variations of the samples are presented in Table 1.

Figure 6 shows the evolution of a phthalic acid sample deposited under a thin layer of martian soil analogue. A shielding effect of the mineral was expected. Indeed such a protective effect was measured during a previous exposure experiment conducted outside the MIR station (Boillot et al., 2002). Surprisingly, it appears that, in this case, the presence of the martian soil analogue increased the photolysis rate by a factor of 1.5. We observed the same factor for AIB. The halflives of AIB and phthalic acid are, respectively, $184 \pm 81$ and $167 \pm 20 \mathrm{~h}$ (Table 2 ). No data are available for mixtures of trimesic acid and martian soil analogue, as we failed to prepare suitable samples in due time before the mission. Results for mixtures of mellitic acid and soil analogue are not straightforward. Both exposed and non-exposed samples experienced major changes as shown in Fig. 7. The shape of the spectra differs, from which we deduced that the contact between the organic compound and the mineral layer induces a conversion of mellitic acid into a molecule that has not been identified to date. Nevertheless, we compared the area of the IR spectra before and after the flight for each sample of mellitic acid. We know that results of this comparison are not pertinent because the molecules are different, but it is an indicator of the photostability of this new compound. It appears that this new compound seemed to be more degraded in the cells that were exposed, in which case it can be concluded that the compound is photodissociated during the exposure.

\subsection{Reflection results: qualitative data}

Fourier transform infrared spectroscopy analyses by transmission were followed by an extraction of the quartz windows from the cells. The windows were analyzed by

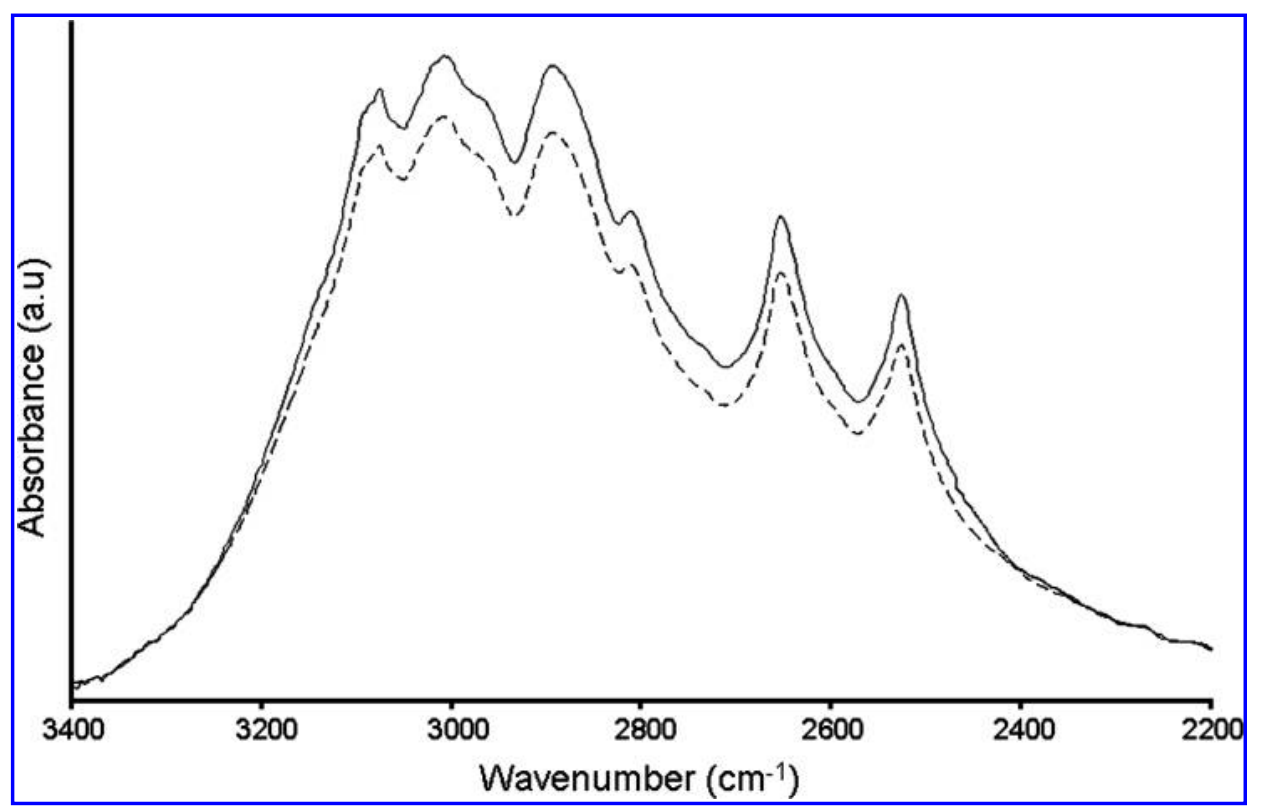

FIG. 6. IR spectra of phthalic acid before (line) and after (dotted line) the flight in orbit in the $4000-2080 \mathrm{~cm}^{-1}$ wavelength range with a $4 \mathrm{~cm}^{-1}$ resolution. The used blank is the quartz window with an analogous martian soil deposit before the deposit of phthalic acid. 


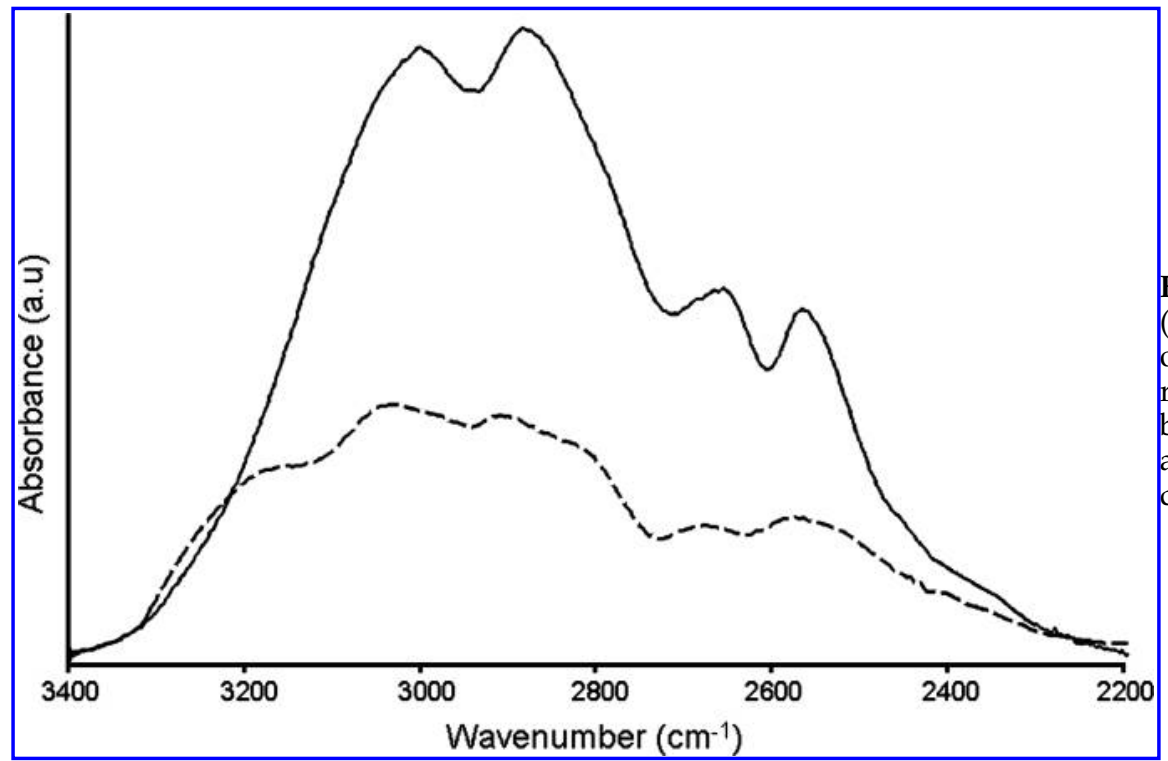

FIG. 7. IR spectra of mellitic acid before (line) and after (dotted line) the flight in orbit in the $4000-2080 \mathrm{~cm}^{-1}$ wavelength range with a $4 \mathrm{~cm}^{-1}$ resolution. The used blank is the quartz window with an analogous martian soil deposit before the deposit of mellitic acid.

attenuated total reflectance spectroscopy with the intent to benefit from an extended spectral range to determine whether new solid compounds were produced during the irradiation. Results for AIB are shown in Fig. 8; no new spectral feature can be observed in the spectra (whether with or without mineral matrix). We also observed no change in the shape of the IR spectra of phthalic acid, whether with or without soil (Fig. 9), and trimesic acid without soil (Fig. 10).
Unfortunately, mellitic acid samples deteriorated during the extraction of the window, and the data are not exploitable.

\subsection{Laboratory experiments: quantitative and qualitative results}

The laboratory experiments (MOMIE) provided information about the evolution of the targeted organic molecules.

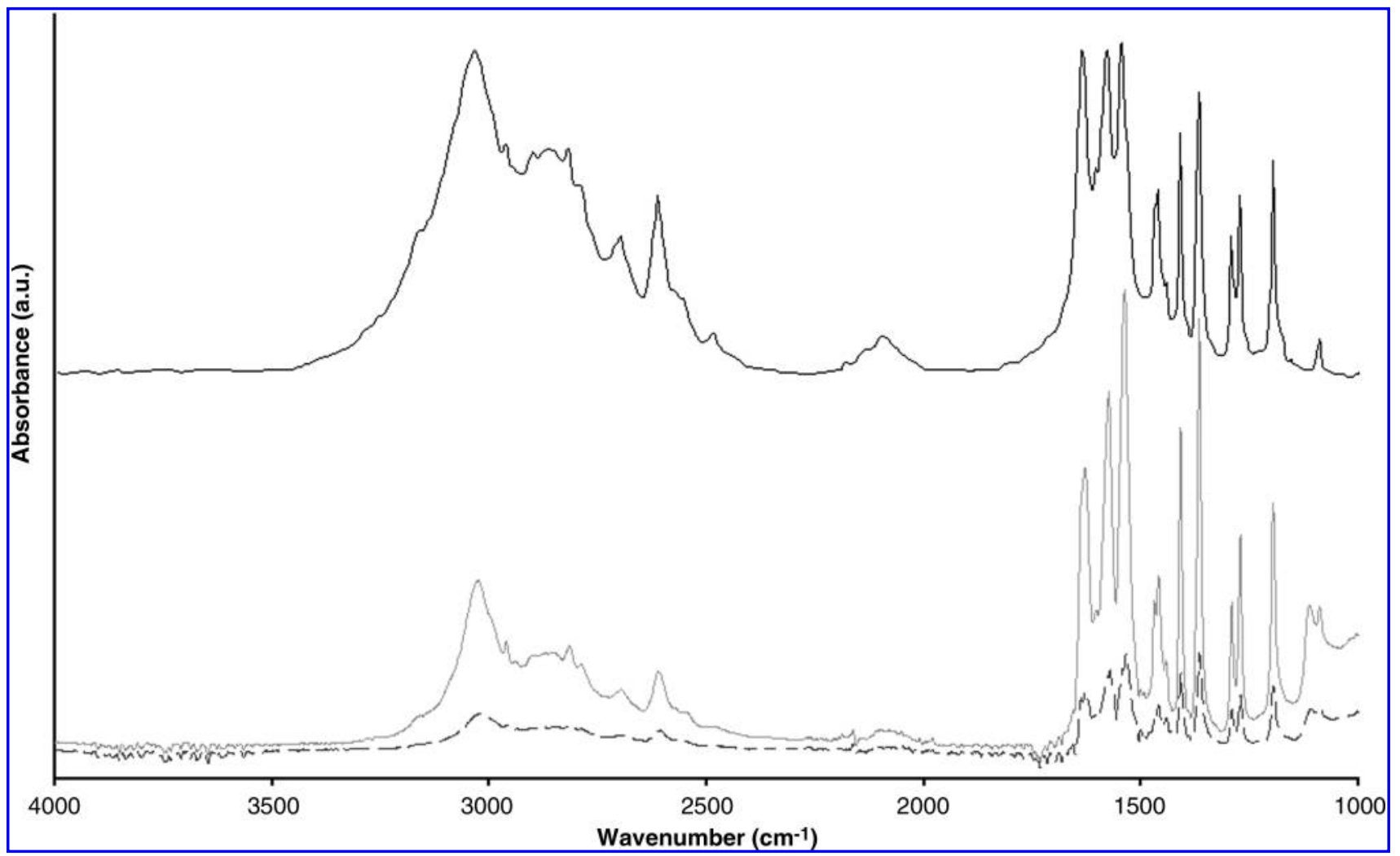

FIG. 8. Reflection IR spectra (bottom) of exposed AIB samples with (dotted line) and without (line) the mineral matrix after the flight in orbit in the $4000-1000 \mathrm{~cm}^{-1}$ range for a $1 \mathrm{~cm}^{-1}$ resolution. The black spectrum is the reference (top). The used blank for the AIB samples with soil is a quartz window with a martian soil analogue deposit. 


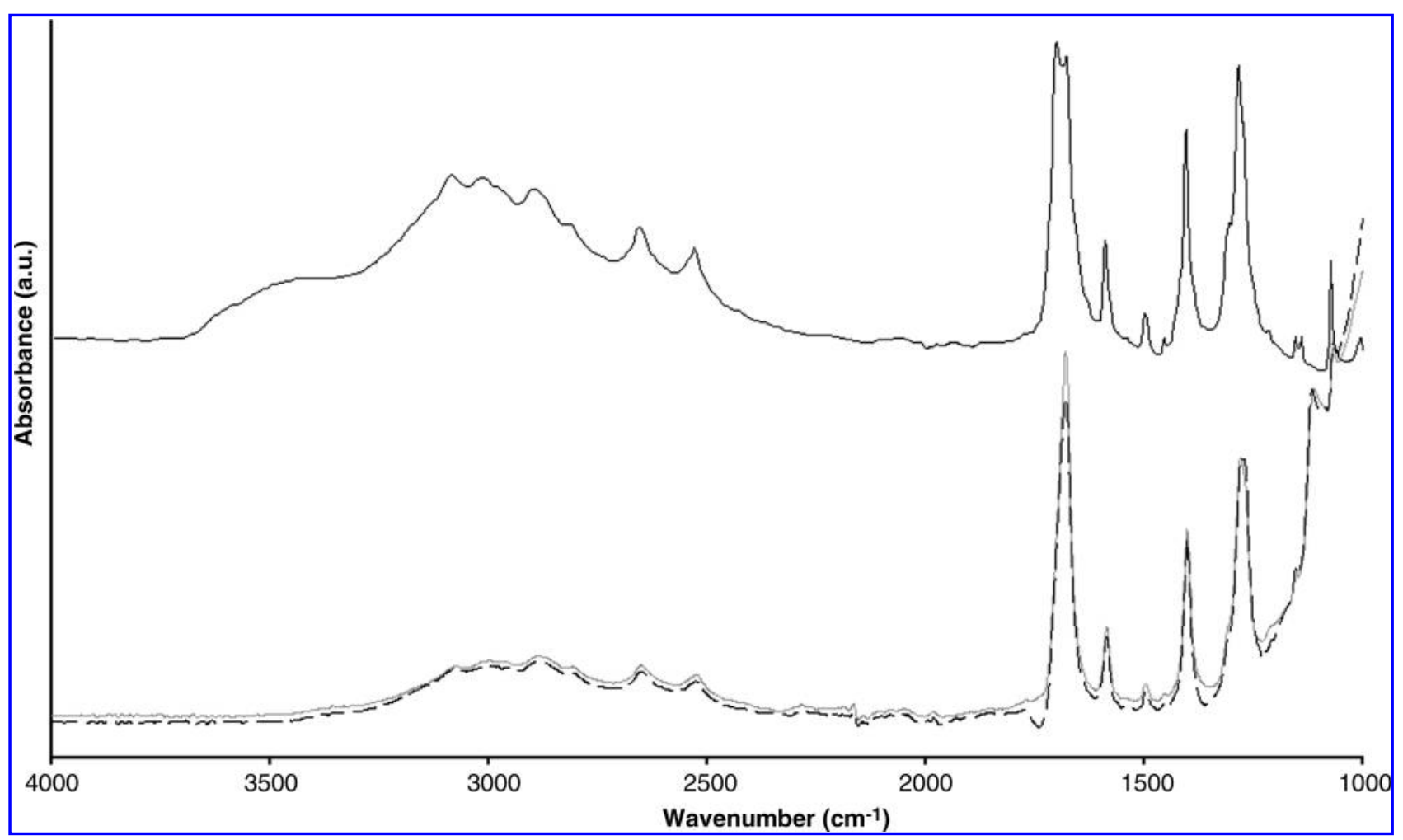

FIG. 9. Reflection IR spectra (bottom) of exposed phthalic samples with (dotted line) and without (line) mineral matrix after the flight in orbit in the $4000-1000 \mathrm{~cm}^{-1}$ range for a $1 \mathrm{~cm}^{-1}$ resolution. The black spectrum is the reference (top). The used blank for the phthalic samples with soil is a quartz window with a martian soil analogue deposit. The strong absorbance around $1200 \mathrm{~cm}^{-1}$ corresponds to the absorption of the quartz window.

We observed that AIB, phthalic, and trimesic acids were destroyed if directly exposed to UV radiation. In the laboratory, the half-lives of $\mathrm{AIB}$, phthalic, and trimesic acids were estimated to be $10 \pm 3,41 \pm 7$, and $21 \pm 5 \mathrm{~h}$, respectively (Fig. 11). Measurements as a function of time during these laboratory experiments confirmed that the photolysis followed a first-order decay as was assumed previously. Conversely, analyses of the mellitic acid irradiated sample spectra (irradiation time more than $30 \mathrm{~h}$ ) indicated that a new IR absorption spectrum appeared by comparison with the non-irradiated mellitic acid spectrum. Results on mellitic acid have already been published (Stalport et al., 2009) and show that this compound is converted into a UV resistant when irradiated with UV light. This compound was identified to be benzenehexacarboxylic acid-trianhydride $\left(\mathrm{C}_{12} \mathrm{O}_{9}\right)$. Nevertheless, we focused on the area evolution of a peak of mellitic acid that is not present in the new compound spectrum, and we determined a transformation by photolysis with a half-life value equal to $4 \pm 1 \mathrm{~h}$ (Fig. 11).

\section{Discussion}

Our results show that all the carboxylic acids studied interacted with UV radiation. The direct exposure to UV radiation led to their partial photodissociation, and there was no evidence to indicate that new compounds in the solid phase were produced from AIB, phthalic, and trimesic acids (we cannot make the same conclusion for mellitic acid due to the lack of a complete data set). The degradation products are released in the gaseous phase and cannot be analyzed with our current experimental setup in the laboratory as well as in orbit. To compare the results obtained during orbit exposure and in the laboratory, we determined the UV flux from the Sun and from the UV source that reached the samples. We focused on the UV range of 200-260 nm because the targeted molecules mainly absorb UV radiation in this range (Fig. 4). The integrated flux in this wavelength region for the Sun is $3.2 \mathrm{~W} / \mathrm{m}^{2}$ (Thuillier et al., 2004), whereas it is $7 \pm 2 \mathrm{~W} / \mathrm{m}^{2}$ for the lamp. The calibration of the half-lives measured in the laboratory gives values of $22 \pm 6,90 \pm 15$, $46 \pm 11$, and $9 \pm 2 \mathrm{~h}$ for AIB, phthalic, trimesic, and mellitic acids, respectively, under "low Earth orbit" conditions. The results appear to be relatively close for phthalic, trimesic, and mellitic acids, and allowed us to validate both laboratory and low Earth orbit experiments. We noted ratios of 1:2.9 for phthalic acid, 1:2 for trimesic acid, and 4.8 for mellitic acid. The differences could be explained by the experimental conditions, such as the control of the temperature or the transmission properties of the quartz window in the $200-260 \mathrm{~nm}$ range (quartz is transparent, but the transmission is not total) and some differences in the shape of the laboratory lamp and solar spectra. With regard to AIB, the ratio is higher $(1: 13)$. This result could be explained by the fact that the UV range absorption of AIB starts below $240 \mathrm{~nm}$ and seems to increase significantly for wavelengths below $200 \mathrm{~nm}$. The quartz windows absorb wavelengths below $200 \mathrm{~nm}$, whereas the 


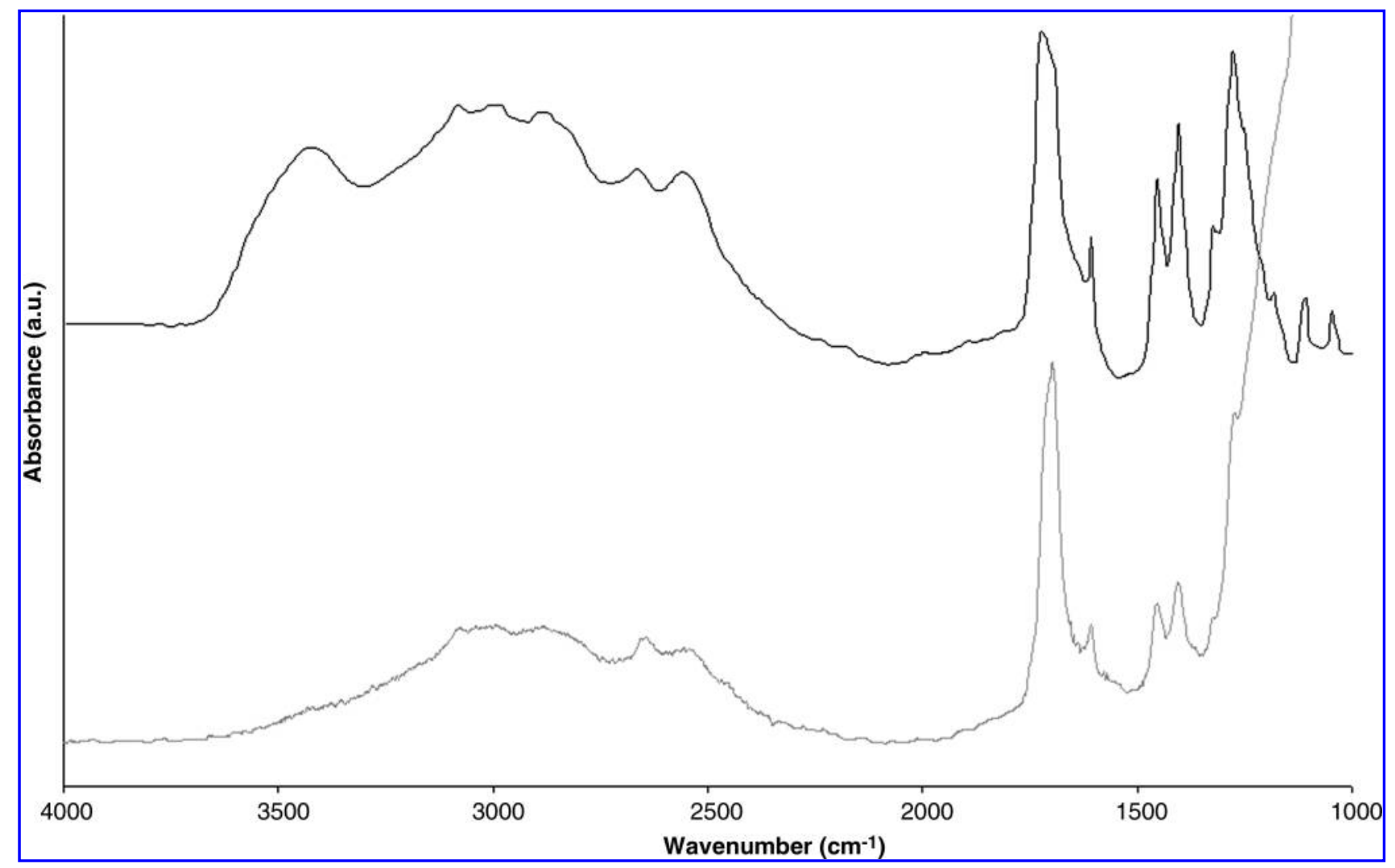

FIG. 10. Reflection IR spectrum (bottom) of exposed trimesic acid samples without mineral matrix after the flight in orbit in the $4000-1000 \mathrm{~cm}^{-1}$ range for a $1 \mathrm{~cm}^{-1}$ resolution. The black spectrum is the reference (top). The strong absorbance around $1200 \mathrm{~cm}^{-1}$ corresponds to the absorption of the quartz window.

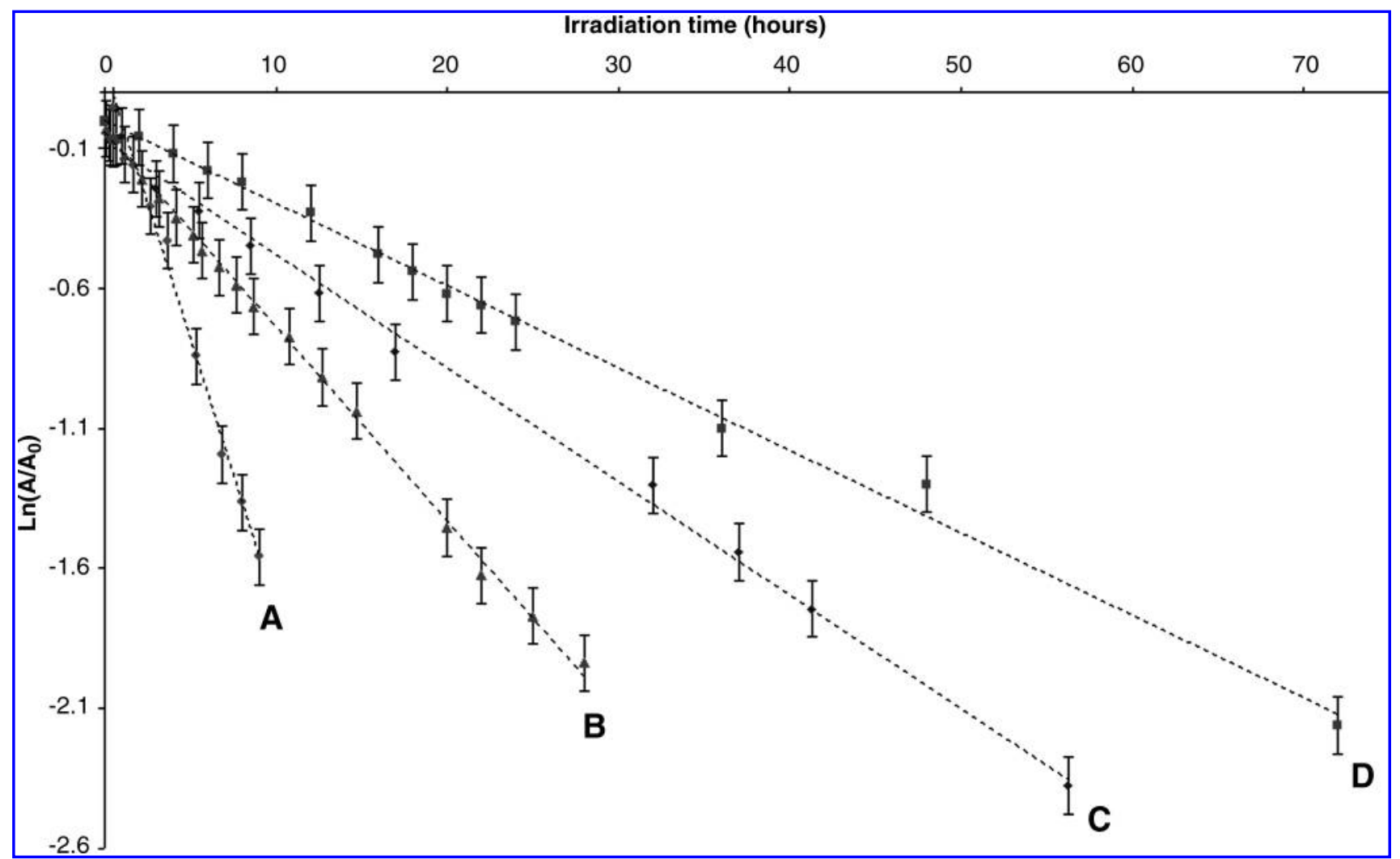

FIG. 11. The natural logarithm of the normalized integrated absorbance $\left(\operatorname{Ln}\left(A / A_{0}\right)\right)$, plotted against time, for mellitic acid (A), AIB (B), trimesic acid (C), and phthalic acid (D). The linear correlation for mellitic acid has been obtained from one band. 
samples in the laboratory were exposed to wavelengths between 190 and $200 \mathrm{~nm}$. We can assume that radiation in this wavelength range has more importance for the evolution of AIB.

The second step was to extrapolate these results to the martian UV surface conditions. The integrated flux in the 200-260 nm wavelength range would be $1.1 \pm 0.2 \mathrm{~W} / \mathrm{m}^{2}$ (Cockell et al., 2000; Patel et al., 2002). Taking into account both laboratory and space experiments, the half-lives of AIB, phthalic, trimesic, and mellitic acids would be in the range of 44-1062, 218-925, 122-317, and 19-169 h, respectively (Table 2). From these values, it is possible to estimate the amount of these organic compounds in the martian regolith over time. The accumulation of such organic molecules would be due to the difference between their production/intake rates [estimated to between $2.4 \times 10^{7} \mathrm{~g} /$ year (Benner et al., 2000) and $2.4 \times 10^{8} \mathrm{~g} /$ year (Flynn, 1996)] and the different pathways that led to their destruction (UV radiation, for example). If the organic compounds were uniformly deposited at the surface of Mars and mixed into the regolith to a depth of $1 \mathrm{~cm}$ [UV radiation is believed to penetrate only the first millimeters of the martian regolith, except in water ice, where the penetration would be several centimeters (Cockell and Raven, 2004), and only a few centimeters of the soil would be recycled by winds], then the maximal concentration by weight of the organics would be $10 \mathrm{ppt}$ (with a maximal repartition on the surface of Mars $\approx 3 \times 10^{-7} \mathrm{~g} / \mathrm{m}^{2}$ and a density of the martian regolith $\approx 4 \mathrm{~g} / \mathrm{cm}^{3}$ ). At this concentration, these molecules could not be detected on the surface of Mars if they were exposed to current levels of UV radiation; thus they would not be the best molecular targets in the search for organic compounds on Mars.

Finally, the organic molecules selected for the UVolution experiment were also exposed in the presence of an analogous martian soil. Rather than a shielding effect from the mineral matrix by absorption of the UV radiation, the photodestruction rate increased. The half-lives of AIB and phthalic acid would be $643 \pm 317$ and $506 \pm 64 \mathrm{~h}$, respectively, under martian environmental conditions (Table 2). Mellitic acid seems to be unstable when in the presence of the soil, and produces a non-radiotolerant compound.

The interaction of UV radiation and the mineral matrix would be a catalyzer of the sample photodecomposition. Photocatalytic oxidation can be responsible for organic degradation of organic compounds in ordinary terrestrial sand dunes (Sancier and Wise, 1981). Results of our experiments, therefore, imply that a martian soil analogue might play a role in the photocatalytic degradation of organic compounds on Mars. Several laboratory experiments have been conducted to investigate the interaction of UV radiation with a mineral matrix (Chun et al., 1978; Pang et al., 1982; Yen et al., 2000). Yen et al. (2000) showed that the interaction of UV radiation with a mineral matrix (labradorite, feldspar) and an oxygen-rich atmosphere could produce one or more inorganic superoxides or peroxides that are able to destroy the organic matter. Chun et al. (1978) and Pang et al. (1982) showed that $\mathrm{TiO}_{2}$ catalyzed the oxidation of organics in the presence of oxygen. In our experiment, no rich oxygen atmosphere was present, but the JSC Mars-1 soil contained $\mathrm{TiO}_{2}$, as does the martian regolith (Allen et al., 1998). The presence of $\mathrm{TiO}_{2}$ could then explain why carboxylic acids were destroyed faster. We intend to develop new laboratory experiments to better characterize this process. Actually, we improved a second version of the MOMIE experiment focused on oxidation processes on the surface of Mars with and without UV radiation, and new laboratory data are expected soon.

\section{Conclusion}

The UVolution low Earth orbit experiment involved the exposure of organic molecules of astrobiological interest to solar UV photons. Some of the samples were selected to study the behavior and stability of organic molecules (AIB, phthalic, trimesic, and mellitic acids) that may be present on Mars. Our data show that the targeted molecules are not photostable because they were partially destroyed after only a few hours of exposure to solar UV radiation. Laboratory experiments confirmed this result for AIB, phthalic, and trimesic acids. The main divergence concerns the evolution of mellitic acid; orbital data indicate that this molecule is destroyed, while laboratory experiment results show that a new radiotolerant compound could be produced. We attributed this significant difference to the short time of exposure to UV photons in orbit compared to the actual photon dose in the laboratory. Indeed, the energy deposit in low Earth orbit would require at least 66 days of direct exposure.

The photolysis of the targeted molecules in the presence of an analogous martian soil increases the photodestruction rate of phthalic acid and AIB. Mellitic acid is not stable with this soil and would produce a new compound (still to be identified), which is in turn also efficiently photolyzed. Hence, these organic compounds would be rapidly destroyed on the surface of Mars if they are directly exposed. Thus they are not the best molecular targets to consider in the search for organic compounds on the surface of Mars.

New data about the photostability of martian-related organic compounds will soon be available. Phthalic and mellitic acid samples in quartz cells have indeed been among the samples accommodated in the PROCESS experiment. PROCESS was the second step of these low Earth orbit experiments and was part of the EXPOSE-Eutef ESA exposure facility. The targeted samples were exposed on the outside of Columbus module from February 2008 until September 2009 (Cottin et al., 2008). PROCESS is quite similar to UVolution (the same kind of hardware and samples), except that a longer exposure time to solar UV radiation is expected (10-20 times more than during the Biopan-6 mission).

\section{Acknowledgments}

This program has been selected by ESA in the frame of the AO Life and Physical Sciences and Applied Research Projects 2004. The authors would like to acknowledge the support of ESA (especially René Demets), CNES (especially Michel Viso for the human, financial, and technical support), French Program for Planetology (PNP), COMAT aerospace (Toulouse, France), and Kayser Threde (Munchen, Germany). The authors also acknowledge the reviewers and Daniel Glavin for helpful comments.

\section{Author Disclosure Statement}

No competing financial interests exist. 


\section{Abbreviations}

AIB, $\alpha$-aminoisobutyric acid; GCMS, gas chromatographmass spectrometer; MOMIE, Martian Organic Material Irradiation and Evolution.

\section{References}

Allen, C.C., Morris, R.V., Jager, K.M., Golden, D.C., Lindstrom, D.J., Lindstrom, M.M., and Lockwood, J.P. (1998) Martian regolith simulant JSC Mars-1 [abstract 1690]. In $29^{\text {th }}$ Lunar and Planetary Science Conference Abstracts, Lunar and Planetary Institute, Houston.

Barbier, B., Henin, O., Boillot, F., Chabin, A., Chaput, D., and Brack, A. (2002) Exposure of amino acids and derivatives in the Earth orbit. Planet. Space Sci. 50:353-359.

Benner, S.A., Devine, K.G., Matveeva, L.N., and Powell, D.H. (2000) The missing organic molecules on Mars. Proc. Natl. Acad. Sci. U.S.A. 97:2425-2430.

Bibring, J.-P., Langevin, Y., Mustard, J.F., Poulet, F.A., Arvidson, R., Gendrin, A., Gondet, B., Mangold, N., Pinet, P., Forget, F., and the OMEGA Team. (2006) Global mineralogical and aqueous Mars history derived from OMEGA/Mars Express data. Science 312:400-404.

Biemann, K., Oro, J., Toulmin, P., III, Orgel, L.E., Nier, A.O., Anderson, D.M., Flory, D., Diaz, A.V., Rushneck, D.R., and Simmonds, P.G. (1976) Search for organic and volatile inorganic compounds in two surface samples from the Chryse Planitia region of Mars. Science 194:72-76.

Biemann, K., Oro, J., Toulmin, P., Orgel, L.E., Nier, A.O., Anderson, D.M., Flory, D., Diaz, A.V., Rushneck, D.R., and Simmonds, P.G. (1977) The search for organic substances and inorganic volatile compounds in the surface of Mars. $[$. Geophys. Res. 82:4641-4658.

Boillot, F., Chabin, A., Buré, C., Venet, M., Belsky, A., BertrandUrbaniak, M., Delmas, A., Brack, A., and Barbier, B. (2002) The Perseus Exobiology mission on MIR: behaviour of amino acids and peptides in Earth orbit. Orig. Life Evol. Biosph. 32:359-385.

Botta, O. and Bada, J.L. (2002) Extraterrestrial organic compounds in meteorites. Surveys in Geophysics 23:411-467.

Brinton, K.L.F., Engrand, C., Glavin, D.P., Bada, J.L., and Maurette, M. (1998) A search for extraterrestrial amino acids in carbonaceous Antarctic micrometeorites. Orig. Life Evol. Biosph. 28:413-424.

Bullock, M.A., Stoker, C.R., McKay, C.P., and Zent, A.P. (1994) A coupled soil-atmosphere model of $\mathrm{H}_{2} \mathrm{O}_{2}$ on Mars. Icarus 107:142-154.

Cabane, M., Coll, P., Szopa, C., Israël, G., Raulin, F., Sternberg, R., Mahaffy, P., Person, A., Rodier, C., Navarro-Gonzalez, R., Niemann, H., Harpold, D., and Brinckerhoff, W. (2004) Did life exist on Mars? Search for organic and inorganic signatures, one of the goals for "SAM" (sample analysis at Mars). Adv. Space Res. 33:2240-2245.

Chun, S.F.S., Pang, K.D., and Cutts, J.A. (1978) Photocatalytic oxidation of organic compounds on Mars. Nature 274:875-876.

Clancy, R.T., Sandor, B.J., and Moriarty-Schieven, G.H. (2004) A measurement of the $362 \mathrm{GHz}$ absorption line of Mars atmospheric $\mathrm{H}_{2} \mathrm{O}_{2}$. Icarus 168:116-121.

Clemett, S.J., Chillier, X.D.F., Gillette, S., Zare, R.N., Maurette, M., Engrand, C., and Kurat, G. (1998) Observation of indigenous polycyclic aromatic hydrocarbons in "giant" carbonaceous Antarctic micrometeorites. Orig. Life Evol. Biosph. 28: $425-448$

Cockell, C.S. and Raven, J.A. (2004) Zones of photosynthetic potential on Mars and the early Earth. Icarus 169:300-310.
Cockell, C.S., Catling, D.C., Davis, W.L., Snook, K., Kepner, R.L., Lee, P., and McKay, C.P. (2000) The ultraviolet environment of Mars: biological implications past, present, and future. Icarus 146:343-359.

Cottin, H., Gazeau, M.C., and Raulin, F. (1999) Cometary organic chemistry: a review from observations, numerical and experimental simulations. Planet. Space Sci. 47:1141-1162.

Cottin, H., Coll, P., Coscia, D., Fray, N., Guan, Y.Y., Macari, F., Raulin, F., Rivron, C., Stalport, F., Szopa, C., Chaput, D., Viso, M., Bertrand, M., Chabin, A., Thirkell, L., Westall, F., and Brack, A. (2008) Heterogeneous solid/gas chemistry of organic compounds related to comets, meteorites, Titan, and Mars: laboratory and in lower Earth orbit experiments. Adv. Space Res. 42:2019-2035.

Demets, R., Schulte, W., and Baglioni, P. (2005) The past, present and future of Biopan. Adv. Space Res. 36:311-316.

Encrenaz, T., Bézard, B., Greathouse, T.K., Richter, M.J., Lacy, J.H., Atreya, S.K., Wong, A.S., Lebonnois, S., Lefèvre, F., and Forget, F. (2004) Hydrogen peroxide on Mars: evidence for spatial and seasonal variations. Icarus 170:424-429.

Flynn, G.J. (1996) The delivery of organic matter from asteroids and comets to the early surface of Mars. Earth Moon Planets 72:469-474.

Formisano, V., Atreya, S., Encrenaz, T., Ignatiev, N., and Giuranna, M. (2004) Detection of methane in the atmosphere of Mars. Science 306:1758-1761.

Glavin, D.P., Matrajt, G., and Bada, J.L. (2004) Re-examination of amino acids in Antarctic micrometeorites. Adv. Space Res. 33:106-113.

Hecht, M.H., Catling, D.C., Clark, B.C., Deflores, L., Gospodinova, K., Kapit, J., Kounaves, S.P., Ming, D.W., Quinn, R.C., West, S.J., and Young, S.M.M. (2009) Perchlorate in martian soil: evidence and implications [abstract 2420]. In $40^{\text {th }}$ Lunar and Planetary Science Conference Abstracts, Lunar and Planetary Institute, Houston.

Hubbard, J.S., Hardy, J.P., and Horowitz, N.H. (1971) Photocatalytic production of organic compounds from $\mathrm{CO}$ and $\mathrm{H}_{2} \mathrm{O}$ in a simulated martian atmosphere. Proc. Natl. Acad. Sci. U.S.A. $68: 574-578$.

Hubbard, J.S., Hardy, J.P., Voecks, G.E., and Golub, E.E. (1973) Photocatalytic synthesis of organic compounds from CO and water: involvement of surfaces in the formation and stabilization of products. L. Mol. Evol. 2:149-166.

Krasnopolsky, V.A., Maillard, J.P., and Owen, T.C. (2004) Detection of methane in the martian atmosphere: evidence for life? Icarus 172:537-547.

Kuhn, W.R. and Atreya, S.K. (1979) Solar radiation incident on the martian surface. J. Mol. Evol. 14:57-64.

Navarro-Gonzalez, R., Navarro, K.F., de la Rosa, J., Iñiguez, E., Molina, P., Miranda, L.D., Morales, P., Cienfuegos, E., Coll, P., Raulin, F., Amils, R., and McKay, C.P. (2006) The limitations on organic detection in Mars-like soils by thermal volatilization-gas chromatography-MS and their implications for the Viking results. Proc. Natl. Acad. Sci. U.S.A. 103:1608916094.

Oro, J. and Holzer, G. (1979) The photolytic degradation and oxidation of organic compounds under simulated martian conditions. L. Mol. Evol. 14:153-160.

Pang, K.D., Chun, S.F.S., Ajello, J.M., Nansheng, Z., and Minji, L. (1982) Organic and inorganic interpretations of the martian ultraviolet infrared reflectance spectrum. Nature 295:43-46.

Patel, M.R., Zarnecki, J.C., and Catling, D.C. (2002) Ultraviolet radiation on the surface of Mars and the Beagle 2 UV sensor. Planet. Space Sci. 50:915-927. 
Pizzarello, S., Cooper, G.W., and Flynn, G.J. (2006) The nature and distribution of the organic material in carbonaceous chondrites and interplanetary dust particles. In Meteorites and the Early Solar System II, edited by D.S. Lauretta and H.Y. McSween, University of Arizona Press, Tucson, pp 625-651.

Sancier, K.M. and Wise, H. (1981) Photoassisted oxidation of organic material catalyzed by sand. In Atmospheric Environment, Pergamon, Tarrytown, NY, pp 639-640.

Simoneit, B.R.T., Summons, R.E., and Jahnke, L.L. (1998) Biomarkers as tracers for life on early Earth and Mars. Orig. Life Evol. Biosph. 28:475-483.

Squyres, S.W., Arvidson, R.E., Bell, J.F., Brückner, J., Cabrol, N.A., Calvin, W., Carr, M.H., Christensen, P.R., Clark, B.C., Crumpler, L., Des Marais, D.J., d'Uston, C., Economou, T., Farmer, J., Farrand, W., Folkner, W., Golombek, M., Gorevan, S., Grant, J.A., Greeley, R., Grotzinger, J., Haskin, L., Herkenhoff, K.E., Hviid, S., Johnson, J., Klingelhöfer, G., Knoll, A.H., Landis, G., Lemmon, M., Li, R., Madsen, M.B., Malin, M.C., McLennan, S.M., McSween, H.Y., Ming, D.W., Moersch, J., Morris, R.V., Parker, T., Rice, J.W., Jr., Richter, L., Rieder, R., Sims, M., Smith, M., Smith, P., Soderblom, L.A., Sullivan, R., Wänke, H., Wdowiak, T., Wolff, M., and Yen, A. (2004) The Opportunity Rover's Athena science investigation at Meridiani Planum, Mars. Science 306:1698-1703.

Stalport, F., Coll, P., Szopa, C., and Raulin, F. (2008) Search for organic molecules at the Mars surface: the "Martian Organic Material Irradiation and Evolution" (MOMIE) project. Adv. Space Res. 42:2014-2018.

Stalport, F., Coll, P., Szopa, C., Cottin, H., and Raulin, F. (2009) Investigating the photostability of carboxylic acids exposed to Mars surface ultraviolet radiation conditions. Astrobiology 9:543-549.
Stoker, C.R. and Bullock, M.A. (1997) Organic degradation under simulated martian conditions. I. Geophys. Res. 102:1088110888.

ten Kate, I.L., Garry, J.R.C., Peeters, Z., Quinn, R., Foing, B., and Ehrenfreund, P. (2005) Amino acid photostability on the martian surface. Meteorit. Planet. Sci. 40:1185-1193.

ten Kate, I.L., Garry, J.R.C., Peeters, Z., Foing, B., and Ehrenfreund, P. (2006) The effects of martian near surface conditions on the photochemistry of amino acids. Planet. Space Sci. 54:296-302.

Thuillier, G., Floyd, L., Woods, T.N., Cebula, R., Hilsenrath, E., Hersé, M., and Labs, D. (2004) Solar irradiance reference spectra for two solar active levels. Adv. Space Res. 34:256-261.

Wong, A.S., Atreya, S.K., Formisano, V., Encrenaz, T., and Ignatiev, N.I. (2004) Atmospheric photochemistry above possible martian hot spots. Adv. Space Res. 33:2236-2239.

Yen, A.S., Kim, S.S., Hecht, M.H., Frant, M.S., and Murray, B. (2000) Evidence that the reactivity of the martian soil is due to superoxide ions. Science 289:1909-1912.

Address correspondence to: Dr. Fabien Stalport

Code 699

NASA/GSFC 8800 Greenbelt Rd. Greenbelt, MD 20771

USA

E-mail: Fabien.Stalport@lisa.univ-paris12.fr

Submitted 22 July 2009

Accepted 23 March 2010 
